Peer-Reviewed Article

ISSN: 2162-3104 Print/ ISSN: 2166-3750 Online

Volume 5, Issue 3 (2015), pp. 208-227

(C) Journal of International Students

http://jistudents.org/

\title{
Japanese Exchange Students' Academic and Social Struggles at an American University
}

\author{
Takahiro Sato, PhD \\ Kent State University (USA) \\ Samuel R. Hodge, PhD \\ The Ohio State University (USA)
}

\begin{abstract}
The purpose of this study was to identify and analyze the views of exchange students from Asia about their academic and social experiences at an American university. The participants were eight exchange students from Japan (four men and four women). This study was descriptivequalitative (Patton, 2002). The data sources were a demographic survey and two semi-structured interviews conducted during the participants' study abroad sojourn. The interview data were analyzed using the constant comparative method (Merriam, 1998). The emergent themes were (a) social distance contributes to academic struggles, (b) collectivism positioned against individualism, (c) isolation in group discussions, and (d) professors' negativity. We include recommendations aimed at improving international students' academic and social experiences at American universities.
\end{abstract}

Keywords: Japanese, International Students, Academic and Social Experiences, Exchange Students, Struggles

International students are an increasingly vibrant source of diversity on college and university campuses in the United States (US). They add new perspectives to academic lectures and can enhance student and faculty appreciation for other countries and cultures (Bevis, 2002; Harrison, 2002). In the 2013-14 academic year, there were 886,052 international students enrolled in American colleges and universities (Open Doors 2014 Report, 2014). Students from the top three places of origin (India, China, and South Korea) comprised approximately $50 \%$ of all international students enrolled in American colleges and universities (Institute for International Education [IIE] Network, 2014). According to the IIE Network (2014), globalization has changed the way the world works as such employers and companies increasingly seek potential 
graduates who have international skills and expertise. Studying abroad must be viewed as an essential component of a college degree and critical to preparing future leaders.

The experience of international students within a new culture has important psychological implications due to its effects on performance and functioning (Robie \& Ryan, 1996). Consistently, research has shown that international students are likely to face various cross-cultural adjustment problems such as adapting to new roles, academic difficulties, language challenges, financial problems, homesickness, deficient study skills, and lack of assertiveness (Barratt \& Huba, 1994). Though not isolated to this population, Asian students studying abroad in the US often experience such issues and difficulties.

Studies show that some international students at American colleges and universities experience academic and language difficulties exacerbated by cultural differences between their native countries and the dominant culture. Over the years, studies have revealed that many international students are often disappointed with their language progress while abroad (Bradley \& Bradley, 1984; Bretag, Horrocks \& Smith, 2002; Hellsten \& Prescott, 2004). Often, such students are not comfortable with their reading speed or comprehension. They also identify that difficulty in understanding spoken languages - even after they have spent a semester or year studying abroad. Zhang and Mi (2010) analyzed the length of study and academic disciplines of Chinese international students who attended Australian universities. Unlike previous studies, these authors found that reading was not a problem area for these students. However, students did struggle to exhibit competency in writing and oral presentations in their academic disciplines.

In the past decade, there has been an emergence of studies that explored Asian students' social adjustment and assimilation at predominantly White universities (Samuel, 2004; Sato \& Hodge, 2009; Spurling, 2006). Consistently, research showed that Asian students often felt marginalized, alienated, isolated, and discriminated against due to racism. For instance, Sato and Hodge (2009) studied the experiences of six Asian international doctoral students (Korean, Japanese, Taiwanese) at two major universities in the US. They found that the students faced academic challenges associated with linguistic and cultural differences, along with stressors such as demands on their time and living marginally in society. The students felt that, in order to achieve academic success, they had to assimilate linguistically and culturally to the dominant language and culture of their graduate programs. They also spoke of difficulties in building social relationships with White peers in their graduate programs, which made them feel uncomfortable and hesitant to communicate with these cohorts. In contrast, the Asian students had formed positive bonds with other Asian students at their institutions, and they felt that their cultural values and religious beliefs sustained despite feeling marginalized (Sato \& Hodge, 2009).

Similar to their American counterparts, international students are often likely to encounter adjustment issues during the transition to higher education. However, because they are in a new country facing an unfamiliar language and culture, international students are likely to experience a more difficult college transition than American students (Kaczmarek, Matlock, Merta, Ames, \& Ross, 1994). In that light, examining the experiences of Japanese exchanges students is an important endeavor in a time of increasing international student diversity at educational institutions in the US to better understand and improve their experiences as academic sojourners. The purpose of this study was to identify and analyze Japanese exchange students' views about their academic and social experiences at an American university. The central question was: How did these Japanese exchange students construct (interpret) their academic and social experiences while studying at a major university in the US? 


\section{Method}

\section{Research Design}

The research method was descriptive-qualitative, using an in-depth, semi-structured interviewing approach (Seidman, 1998). This method is well-suited for best understanding complex academic and social phenomena - in this study, with Japanese students regarding their academic sojourn. Moreover, interviewing is a powerful way to gain insight into academic and social cases experienced by individuals in educational contexts (Seidman, 1998). This method is a logical sequence that connects empirical data to the study's purpose, research questions, and its conclusions. Further this method is unique in that it allows the researcher "to acquire data not obtainable in any other way" (Gay, 1996, p. 223). There are certain things that simply cannot be observed, including (but not limited to) past events (e.g., a student's past experiences with classmates), events that occur outside of the researcher's sphere of observation (e.g., a student's reflection on and recall of past social events), and mental processes such as a student's thoughts about her lived experiences. For this reason, this study used focused semi-structured interviews that involved verbal exchanges with Japanese students as an excellent medium for reflection on and articulation of their lived experiences.

\section{Participants and Sampling}

The participants were eight Japanese students (four men and four women) in one-year exchange programs. Seven participants (Otoya, Kazuya, Suguru, Mei, Mako, Chiharu, and Risa) were Japanese, and one participant (Liang) was Chinese. Pseudonyms were used to protect the identities of participants. Otoya, Kazuya, Suguru, Mei, Mako, and Chiharu are Japanese (age between 20-23). Liang was unique participant who was born and raised in China until the third grade of elementary school, then moved to Tokyo with his parents. He consequently speaks, writes, and reads fluently in both Chinese and Japanese languages. In fact, he self-identified as Japanese. Participants were purposefully sampled using maximum variation sampling (Patton, 2002). All participants were undergraduate academic students with varying academic status (freshman through senior), age, gender, number of years lived in the US (minimum 1 year), location and types of high schools or colleges they had attended, and academic majors (i.e., political science, recreation and tourism, English literature, and sociology). The commonality among them, however, was the phenomenon under study of academic experiences as Japanese students.

\section{Data Collection}

Demographic questionnaire. A demographic questionnaire was used to gather background information from participants. The questionnaire consisted of a variety of questions aimed at securing information on participants' age, gender, academic majors, educational background, language learning experiences including ESL and other courses at the host institution, socioeconomic background, financial support, and future plans after graduation or completion of exchange programs. Data were used to develop personal descriptions of the participants and to augment data gleaned from interview transcriptions to further triangulate the findings. If conflicts existed within the different types of data, the lead researcher contacted the relevant participant(s) by e-mail messages for clarification purposes.

Semi-structured interviews. Semi-structured interviews (Patton, 2002) were used to gather data from participants. This involved two separate face-to-face interviews with each 
participant where the lead researcher asked various open-ended questions. All of the participants were enrolled in two ESL modules (beginner, intermediate, or multiple advance levels) in writing composition, grammar, speaking, and listening courses. They were expected to attend daily lectures Monday through Friday for eight weeks. This occurred for all of the courses associated with each module. The researchers decided to interview the participants after they completed each of the series of courses in each of the two modules, because they tried to understand students' academic progress and improvements. Interview questions were derived from extant literature in education and social psychology (Choi, 2006; Spurling, 2006). Prior to data collection, the interview guide was translated from the original English version to the participants' native language, Japanese, using a cross-cultural language translation technique (Banville, Desrosiers, \& Genet-Volet, 2000). This process is summarized below.

The five native Japanese speakers who translated the English questionnaire included the lead researcher - who served as a chair of cross-validation committee for the interview protocol and questionnaire (A) - and four bilingual graduate students (B, C, D, and E) in various departments at universities in the US and Japan. All were fluent in both English and Japanese. First, four translators (B, C, D and E) individually translated the English version of the questions into Japanese. Later, they compared their versions and discussed any differences to arrive at an agreement. The primary researcher (A) then revised the questions as deemed necessary for proper vocabulary, grammar and syntax in Japanese. In Step 2, the interview questionnaire was piloted with three Japanese undergraduate students who had completed a one-year exchange program in the US. They responded to the Japanese version of the questionnaire by writing directly on the questionnaire, underlining any words or expressions they did not understand or about which they were uncertain. Each underlined part was re-examined by the translation committee and modified, as necessary.

The first interview was used to establish the context of the students' experiences. In the initial interviews, participants were asked about their motivation for attending a university in the US. The second interview was used to prompt participants to re-construct the details of their experiences and assimilation at the host institution. A conversational approach was used to further prompt critical reflection and to share the meaningfulness of their experiences, for example, in terms of their status and positioning as an international student as well as issues of isolation, marginalization, and presence.

Translation of the Data: The researchers gave each participant a choice of language preference (either Japanese or English) for the interviews. They all chose to respond to the interview questions in their native Japanese language. Prior to initiating the study, the lead researcher (who is fluent in both English and Japanese languages) recruited two bilingual students in the Education Department to serve as translators and to double-check his translations of the interview data. This was so as to employ the back translation strategy that is regarded as the most appropriate way to ensure proper cross-cultural translation and validation (Vallerand, 1989), which requires at least two translators who speak the same native language. The researchers recruited translators who spoke Japanese, including regional variants of spoken Japanese (Kanto dialect, Kansai dialect, and so forth). After the data collection was completed, the researcher and the two additional translators translated all the interview data into English and compared the content and contexts of the data. All English and Japanese versions of the data were sent to all participants, who then edited the transcribed data and confirmed that all data were accurate. 


\section{Data Reduction, Analysis and Trustworthiness}

The participants' demographic data were analyzed descriptively (Gravetter \& Wallnau, 1996). First, interview data were transcribed from the audio-taped sessions. Later, the researchers listened to each audio-taped interview while reading along with the written transcripts to check for accuracy of transcription, and corrections were made as needed. Then, using the constant comparative method (Merriam, 1998), the researchers independently analyzed the transcripts for units of meaning, and this revealed thematic categories. These data were shared between the researchers, and recurrent themes were identified and analyzed. After independent analysis, the researchers met to ensure verifiability with participants. The participants and researchers reached agreement through a process of examining and reexamining the transcribed data and engaging in dialogue about our interpretations. Narratives were written and agreed upon with direct quotes to illustrate the themes (Lincoln \& Guba, 1986).

Trustworthiness was established through triangulation, member checking, and peer debriefing. Triangulation was used to confirm the accuracy of the data and of our interpretations (Lincoln \& Guba, 1986). Confirmability was established through investigator and data triangulation. As mentioned before, the researchers examined the data both separately and collaboratively (i.e., investigator triangulation) so as to extract the themes (Brantlinger, Jimenez, Klingner, Pugach, \& Richardson, 2005). In terms of data triangulation, the interview data were compared across interviews as a collective corpus and cross-checked with follow-up messages (Brantlinger et al., 2005), from which recurring themes emerged. Member checking was used for verification purposes. The lead researcher e-mailed the transcribed interviews and researchers' interpretations to the individual participants and asked each participant whether the results were accurate and representative of his or her views and experiences. All participants confirmed the accuracy of their respective transcripts and indicated that what they said during the interviews was what they intended to convey. Further, they all agreed with the researchers' interpretations of their comments. In a final step, a peer debriefer, who was trained using Lincoln and Guba's (1986) criteria for establishing trustworthiness, examined the data. The peer debriefer critically examined the accuracy and completeness of the data interpretations. Together, these processes ensured the accuracy and, therefore, trustworthiness of the transcribed data and the interpretations made.

\section{Results}

Four major interrelated and complex themes emerged from the data. They were: (a) social distance contributes to academic struggles; (b) collectivism positioned against individualism; (c) isolation in group discussion; and (d) professors' negativity. The students' experiences were positioned accordingly. These themes and subthemes are discussed below in narrative form, with quotes from participants.

\section{Theme 1: Social Distance contributes to Academic Struggles}

All eight Japanese students had great expectations of improving their English language proficiency through developing friendships with American students. The results showed that all of them felt that they were not well-prepared to master the content and knowledge of their academic major using the limited English they learned in ESL courses. They were demotivated 
to apply the knowledge they learned from the study abroad experience to their future academic and social opportunities. Below we discuss the subthemes that support this theme.

Stranger Anxiety. The first subtheme captures the fact that all participants expected to develop social relationships or friendships with American students while completing the yearlong exchange program. They were frustrated that they might not be able to meet their social goal and expectation of English fluency through the study abroad program. Moreover, they had stranger anxiety "hitomishiri", which means they were reserved around people they did know. Participants observed American students and realized that those who expressed an interest in Japanese culture were most dependable and friendly. Liang said he was hesitant to speak to American students on campus during the first semester because of the social distance from American students. However, he felt that minimizing the social distance helped improve his English proficiency. Therefore, he was motivated to initiate conversations with American students.

I was not hesitant to ask questions to my Japanese friends when I was in Japan. All of my friends helped me and shared their responses and answers. It was easy to make friends there [Japan], but I did not know anyone when I came to this American university. I had to take care of my academics and social stability by myself. That was tough, but I would like to succeed my study abroad experiences here. If I do not understand how to register courses, I asked American students who worked at register office. I kept asking questions until I fully understood. That was good thing that was happening since I attended to this university (Liang - interview).

Liang stated that he was hesitant to speak to American students because he did not want to bother American students in seeking guidance. In Japanese culture, his behavior is called "enryo," which involves inferring and thinking about the psychology of another person from a distance. Similarly, Mei explained that,

When I talked to American students on campus, I felt horrible that they had to deal with my English. Probably, they could not understand words I was saying. I feel horrible and terrible. I felt that as an international student, I am language minority. I sensed hierarchical relationships with American students. The hierarchical relationships made my study abroad experiences from positive to negative. I felt sad about it.....(Mei - interview)

Mei felt uneasy about American students - who had to cope with her lack of Englishspeaking proficiency. She believed that she had difficulty in adjusting from belonging to a dominant language group (Japanese) to belonging to a minority language group in the US. What is more, she felt that there was a hierarchical relationship with American students where she felt subordinate.

Academic Challenges. Although all participants expressed strong hopes of improving their English writing, reading, and speaking competency, seven of the students (Mei, Liang, Chiharu, Mako, Otoya, Suguru, and Kazuya) had the additional goal of enrolling in their academic major courses alongside American students. Although learning English was an important component to academic success, it was not the ultimate goal or objective of their study abroad participation. These seven participants believed that passing the Test of English as a 
Foreign Language (TOEFL) was necessary to be eligible to enroll in their academic majorrelated courses with American students. However, they struggled to pass the tests and earn good grades on their writing assignments, as they encountered cultural mismatches in the use of English. They often misunderstood theoretical concepts and the content of class lectures. This made them feel more challenged, especially because their culture and traditions were outside the dominant culture. For example, Kazuya said that,

When I had a lecture in ESL course, instructors taught American culture and concepts of English languages at the same time... The instructors explained history and tradition of American culture. I knew that purpose of taking ESL classes was to pass the TOEFL and get a chance to enroll in my academic major courses... When I enrolled in my major courses, all of my classmates already knew about history, traditions, and American culture. I could not fully capture what the lecture was about. I think this was cultural mismatch. It could be my English language, but I do not have any American cultural and social backgrounds. That was my problem. (Kazuya - interview)

He meant that he learned writing, reading, and speaking, but felt there was a cultural and linguistic mismatch, so he was unable to use English in authentic and meaningful ways when he attended lectures for his academic major-related courses. Moreover, Suguru mentioned that the transition from taking ESL courses to major-related courses was difficult, because the major related courses do not only require English proficiency but also critical thinking skills.

I think that I need to increase the number of English vocabulary and use the words I learned from ESL courses at various academic settings [e.g., English speaking or composition]. I believe that this learning process is similar when I was taking at university in Japan. I read textbooks repeatedly and used dictionaries for finding academic words I did not know, but I do not know how to apply knowledge to various settings or situations. The major difference between ESL and academic major courses was that I must have critical thinking skills when I wrote papers. I do not think I have been well trained when I was at Japanese university. I realized that memorization does not help to develop critical thinking skills. I need to critically analyze class lecture and content. That was the hardest thing to do. I am struggling so much. I am practicing, but it is very hard (Suguru - interview).

\section{Theme 2: Collectivism positioned against Individualism}

This theme indicates that all participants experienced a dilemma between individualism and collectivism of culture as a function of their different backgrounds. Both American and other international students influenced the participants' academic and social experiences. The participants belonged to one or two Japanese groups aimed at supporting their academic study and personal friendships. The Japanese term 'amae' implies not only dependency or attachment, but also a desire that they may be given preferential treatment by other Japanese students. However, the participants felt 'impatient' or 'time urgency' (aseri in Japanese), realizing that they might not be able to achieve their academic and social goals during the one year exchange program. Chiharu, Megumi, Liang, and Mana, for example, attempted to become more independent (individualism) on campus rather than interdependent (collectivism), but they realized that becoming independent caused social isolation and marginalization from Japanese student groups. 
Aseri (impatience): All participants felt that they should create opportunities to speak English with American students. However, they mostly socialized with Japanese friends because they were much more comfortable with other Japanese peers and found such interactions more enjoyable. They also sought social and academic support from each other during the exchange program. The participants face dilemmas that caused impatience or time urgency. Otoya explained this phenomenon as follows:

When I came to this campus, I was well motivated to learn American culture and English language. I wanted to make American or international friends. However, I lost my confidence of making new friends when the time was passing by, because I was hesitant to talk to new friend. I knew that they did not understand words I was saying. Then, I started to hang out with several groups of Japanese students. I enjoyed and did not have to care about language barriers. There were many Japanese students who come here to enjoy American campus life. They were not motivated to learn English language or academic major related courses. My study time was distracted by Japanese students. At the same time, I was afraid of losing friendships from Japanese groups. I knew that I had to learn how to say "NO", but it was very difficult to do. While I was in Japanese student groups, it was fun and I enjoyed so much. I believe that I should become an independent student who can work hard for achieving my goals and objectives. I always thought that my academic and social experiences are similar with when I was in Japan. Just different location...... I do not think my study abroad experiences are valuable. (Otoya - interview)

Otoya was well-motivated to study English, but he was hesitant to practice it with American students. There were some one-semester exchange students who sought social activities rather than studying English. When Otoya's friends asked him to go out, he could have refused their offers, but he was afraid of being marginalized from the group. Mako tried to become more independent, but she felt isolated.

I feel isolation. I realized that I do not have good American friends, and I believe that American friends cannot be my best friends, because of my language barriers. My purpose of study abroad is to learn English, but now I do not speak Japanese or English language. ...I feel isolation. I have days I did not talk to anyone on campus. I feel lonely. (Mako interview)

Mako was one of the participants who felt the psychological characteristics of aseri (impatience) that she needed to practice English and so should not socialize with Japanese students. She attempted to develop positive psychological stability associated with her academic and social experiences, but her aseri caused isolation.

Amae (dependency and emotional attachment): All participants believed that they should become independent exchange students who represent a role model of being Japanese. However, they had been actively manipulating their Japanese friends' emotions (e.g., prioritizing social interactions with other Japanese students) so as to release their own psychological stress associated with negative social and academic experiences. They needed to be independent and avoided academic and social issues with other Japanese students. They believed that amae is a 
behavior that indicates a special, egocentric, and selfish attitude. However, as long as their friends accepted this and were willing to satisfy their demands, they became intimate.

When I came to this university, I decided that I would not hang out with Japanese students. I tried, but I realized that I would not be able to maximize valuable information and resources. I have an example that when I came here I struggled to find out how to wire my academic tuitions and fees from Japan. I asked the question many times at register offices, the clerks explained to me many times, but I did not understand. Then I asked a Japanese student, she told me how to do. I realized that when I was in trouble, only Japanese students could solve my problems. I also found that when Japanese students made American friends, they introduced them to me. So I can expand social community and network. I believe that there are many benefits when I hang out with Japanese students. (Risa - interview)

Risa also tried to avoid communicating and socializing with Japanese student groups. However, she realized that when she was in trouble, Japanese students became her resources and could help to find solutions. She believed it was beneficial to get along with Japanese students. She felt that some Japanese students become independent; but she said they lost good opportunities to expand their social community.

I think that many American students are not interested in Japanese culture. They do not care about my culture. It is very difficult to find something in common. If I am interested in some professional sport, I may be able to expand conversation, but I am not a sport fan. It is very difficult. On the other hand, when I have a conversation with someone who is interested in Japanese culture, they are willing to know and learn more about my culture. They appreciate when I talked about history, tradition, food, and habits. I can depend on them when I have academic or social problems. (Kazuya - interview)

Kazuya stated that he was unable to find mutual topics of interest for initiating a conversation with American students. Fewer American students were interested in Japanese culture. Therefore, he developed negative impressions about American students who seem to care about American culture only. He said that "when I do not belong to Japanese groups, I do not have anyone I can talk to on campus". He perceived that he is "amaeru-ing" to (being dependent on) other Japanese students. This was important for him in order to sustain social stability during his study abroad. He faced a dilemma whereby he needed to improve his English proficiency, but he did not know how to develop positive social relationships with Americans.

\section{Theme 3: Isolation in Group Discussion}

This theme captured participants shared experiences of feeling like unwelcome outsiders from a foreign land - marginalized, alienated, and alone in their individual circumstances - in their academic major courses. They felt that some of their American classmates behaved in marginalizing and alienating ways toward international students. Typifying this, all participants were disappointed that when they attended classes, American students did not want to interact with international students when professors assigned students to do group discussion.

Ignorance: When the participants enrolled in regular courses, they had several occasions for group discussion with American classmates. However, they felt ignored and marginalized by 
their American classmates. They had the impression that American classmates preferred to find partners with similar backgrounds to their own. For example, Mei was disappointed and emotionally hurt when she asked a classmate to be her group discussion partner.

I am taking inter-cultural communication courses now. Professor organizes a group discussion. I wanted to chat with a student who was sitting behind me, because there was no student who was sitting next to me. I asked the student and he ignored me and he tried to avoid having a discussion with me. I was hurt that I was avoided by American classmate (Mei - interview).

Mei explained that American students could find something in common with classmates who share similar interests and backgrounds. She also stated that "American students were conservative and need to explore diverse perspectives of communication with international students". Further, Liang said that he struggled to ask some questions that were useful for group discussions. He wanted to develop a meaningful discussion and expand the conversation, but did not know how to do so.

I do not know how to do discussion with American classmates. I see that discussion becomes mutual conversations and all students shared their ideas and thoughts about specific content, but I could not. My discussion is one -way conversation that my partner asked me question I answered. I could see that my partner was getting bored and finally there was no conversation at the end of discussion. My partner began to talk with other students in different groups. I am disappointed, but I do not know what to do and how to do (Liang - interview).

Liang believed that discussion must involve an exchange of views through open dialogue. However, his assigned partner started to lose interest and attention during the group discussion because Liang could not expand on the conversation. Liang said that "international students need to learn how to ask good questions that capture American students' personal attention."

Isolation: All participants felt isolation when they participated in group discussions. They believed that they struggled to participate because of the language barrier. However, they realized that American students never helped the international students who called for help during the discussion. Mako, for example, felt extremely isolated, and her classmates never asked her to be a part of a group. She had to ask the professor to find a group for her.

When I paired with classmates, I was hesitant to ask for help. Sometime, classmates did eye contact and found their partners easily. I do not know how to do that. I was one who could not find a partner in the class. I had to ask professor who helped me to find a group for me. It was sad. I felt marginalized. When I participated in the discussion the professor suggested me to join in, of course, I was lonely; there was no way to join in the discussion. Group members did not care about me. I was disappointed. I realized that if I am not assertive to find a partner, no one helps me. I have been in the situations several times in this semester. This type of experience made me feel lonely and I do not think my study abroad is a success. I feel that I do not have any friends here on campus. (Mako - interview) 
Several participants (Liang, Kazuya, Otoya, Rei, and Mei) had similar experiences to Mako. They felt it was important that professors develop rules and routines for group work such as finding partners you do not know well or dividing students into random groups.

\section{Theme 4: Professors' Negativity}

All participants shared similar experiences in that they received negative advice or comments from professors teaching academic major courses. Many professors were concerned and asked them to withdraw from the courses within two weeks after the semester began. They assumed that participants' English proficiency and comprehension were not good enough to pass their courses. No participant received any modification on tests or assignments while enrolled in the academic major courses. Some participants (Liang, Kazuya, Rei, and Mako) felt that professors should modify the test formats and give deadline extensions. They attempted to meet all the requirements set by the professors, but it was time-consuming and they spent a tremendous number of hours completing each assignment.

Excluding International Students: The participants were unable to develop positive relationships with university professors in the classroom. Further, when they visited professors during office hours, their professors shared concerns about the participants' academic progress. Mako, Mei, Risa, Otoya, and Liang were encouraged to withdraw from the courses within the first two weeks of the semester. They were emotionally hurt and disappointed about the professors' unwillingness to provide academic support. Risa, for example, explained the situation as follows.

I cannot tell you about the course name, but there was a course. I still remember that in week 2, a professor gave weekly oral quizzes. I did not understand the questions he said. I struggled so much. I am not sure why he did not use any written quizzes. When his lecture began, I had to take notes. He wrote key words and definitions on blackboard. I could not read words he wrote. Then, I stopped by his office to see him during his office hours. He told me that "why are you taking my class? If you do not understand the content of lecture, why do you not withdraw from my course? He was very negative about me. He encouraged me to take other section of the same course. He was unwillingly to help me. He was not trying to meet individual needs of students. I was mad (Risa - interview).

Risa decided not to withdraw from the course because she was interested in the content. She hoped to challenge and overcome relationship barriers with the professor. Otoya realized that some professors showed favorable responses when students challenge professors' knowledge and teaching competence. When he was taking a criminal justice course, there was a group discussion about a child abuse case. After the professor shared his viewpoint about the case with students, a few students disagreed with the professor's opinion. Otoya was shocked, because Japanese undergraduate students are not allowed to disagree with professors' opinions. However, Otoya gave a negative impression to the professor because he did not participate in the discussion.

When I was taking a course of criminal justice studies, I had to discuss about a child abuse case with classmates. It was sensitive and controversial topic to discuss. I was surprised that 
when a professor shared his opinions about this case with students, two students raised their hands and argued the professor's viewpoints. It was unbelievable to see that students shared opposite views and perspectives about such a controversial topic. However, the professor seems to enjoy and listen students' voices. I am sure that the professor sees me as quiet and maybe bad student. It seems that he was not happy, because I never raised my hand. That was unusual to see the situation from my academic backgrounds. I was not allowed to share my views with my professors in Japan. I am not used to it. It was cultural shock to me. (Otoya - interview)

Otoya felt that there was a cultural difference as to professor's image of the ideal student. He believed that undergraduates must respect professors, who have dignity and authority. He felt that he was excluded by the discussion environment. Otoya believed that if the professor gave him an opportunity to participate in the discussion, he would try his best. However, he could not initiate a discussion with his classmates and professors.

Academic Support. All participants felt that no professors initiated help for the students unless they asked for assistance. The participants believed that in Japan the professors of their academic major courses frequently checked their academic progress, mental health, and social comfort throughout the semester. They believed that American professors prefer to develop academic relationships with students, rather than social relationships. They expected professors to check their understanding of lectures, assignments, and tests. They also feel that professors should give the option of test accommodations. It seems that all participants believed that their professors treated international students and American students on the same footing, but that international students need more time to read text books, take tests, and write papers. For example, Mei and Mako visited student accessibility services, which support the academic progress of students with disabilities. However, they were not officially diagnosed with a disabling condition, so they were not eligible to receive such services. Mei shared her experiences of exclusion from her professors as follows.

My professors of academic major related courses do not modify his or her instructional method, materials, assignments, and tests for international students. Of course, I understood that professors need to treat students equally. However, I need some modifications. For example, I was taking note from power point slides, professors changed slides while I was writing. I was hesitating to ask them to show previous slides. They used unique terminology that was related to academic fields of study. I did not understand those terms. Listening, writing, and reading are difficult to use these skills at the same time. It was hard and tough. I told my professors about language difficulty. I started to visit office hours more frequent than before, so the professors always support Japanese students, but they did not include me during the class lecture. I was hesitant to talk to professor. I need good social relationships with professors (Mei-interview).

Mei stated that she could not keep up with the pace of class lectures. She believed that unless someone asked a professor for help, he or she would not help students. She felt that visiting a professor's office during office hours is regarded as bothering the professors. 


\section{Discussion}

The themes that emerged from this study were that the Japanese students in this sample struggled to overcome cultural dissonance, which means that although they behaved appropriately based on their cultural norms and upbringings, their peers and professors with different cultural backgrounds often inappropriately interpreted and responded to their behavior (Hodge, Murata, \& Lieberman, 2012). Culturally, these Japanese students had difficulty adjusting to American social norms (e.g., social and emotional distance from American students). They prioritized Japanese group members' social goals and objectives rather than individual academic and social goals and objectives during their study abroad (Kobayashi, Kerbo, \& Sharp, 2010). Further, these Japanese students did not assimilate into the American culture or language within their daily lives off-campus, and only minimally so and out of necessity while on the university's campus.

The Japanese exchange students had situational anxiety in regards to communicating in classrooms and on the campus. Situation-specific anxiety directly and negatively affects an individual in specific situations (e.g., speaking in class) or environments (Woodrow, 2006). For example, the Japanese students had a tendency toward neurotic perfectionism in the sense of unrealistic expectations about achieving excellence in their English language proficiency (Nilsson, Butler, Shouse, \& Joshi, 2008). They believed that studying English and enrolling in academic courses should bring their English proficiency to native-English speakers' levels. However, this did not happen. As a result, they experienced high levels of situational anxiety, which led to a fear of failure (e.g., social distance from American students coupled with academic and language challenges) about achieving their goals. In short, cultural adjustment difficulties and challenges may result in situational anxiety (Wilton \& Constantine, 2003). The Japanese students began their studies in Japan, where they were a part of the ethnocultural majority. It turns out they were unprepared to handle intercultural communication with American students at an American university.

The exchange students faced difficulty in writing essays or journal reflections on specific topics that required them to demonstrate critical thinking skills and personal responsibility for their assignments. They had no such difficulty while matriculating in the Japanese educational system. From a cultural perspective, the Japanese students had been taught by their teachers and parents in Japan to show unquestioning respect and submission to authority (Tam, Heng, \& Jiang, 2009). While at the American university they maintained a similar pattern of value-laden to the professor's authority and demonstrated a lack of creative thought (Tam et al., 2009). Jones and Ratcliff (1993) asserted that students' perception of critical thinking skills is dependent on the context in which the teacher sets the learning task. The Japanese students in our sample reported that they had to accept and adopt whatever their Japanese professors said. They were required to memorize the course content, and received few chances to express their opinions. Therefore, they had a hard time in expressing their views and expanding their cultural values during the study abroad experience in the US.

Most troubling, the Japanese students felt marginalized and isolated when they independently sought American friends or English conversation partners on campus. In the Japanese collective culture, an individual student's wishes and goals are subordinated to group goals. Independent coping strategies are regarded as immature and selfish, threatening harmony in social relationships within the group (Cross, 1995). Japanese students also felt and viewed themselves as outsiders on the university's campus. They became emotionally detached from the campus climate (Sato, Hodge, \& Burge-Hall, 2011). Although they were willing to assimilate to 
the campus culture, they found it difficult to do so. They believed that this was because international students tend to have difficulty communicating with American students and do not fully understand the essence of American social gathering patterns.

As such, the Japanese students mostly spent time with peers from Japan. Although it is beneficial for Japanese students to develop supportive relationships with people from their own cultural backgrounds, they also need such relationships with Americans at the university. These exchange students had a hard time adjusting to cross-cultural differences between collectivism and individualism in social interactions and friendships during the study abroad experience. They had academic and social goals; in particular, improving English proficiency and developing positive friendships with American students. However, they chose to join Japanese student groups and they felt impatient (aseri) that during the study abroad experience they had a similar lifestyle to that in Japan. They preferred the close bond and harmony within the Japanese student groups (Cross, 1995). They benefited from spending more time with Japanese student groups so as to reduce academic and social uncertainty and anxiety associated with intercultural encounters between individualism and collectivism (Gudykunst \& Hammer, 1988).

The exchange students felt most comfortable when Japanese friends allowed them to become dependent (amaeru - the verb form of amae) and took them into the Japanese group. This collective culture made it difficult, however, for them to be independent (Okonogi, 1992). They also felt "aseri" (impatience or time urgency) and irritated that they had limited time to learn English. And, they began to compare their English writing, reading, and speaking proficiency with that of other Japanese international students or other international students while enrolled in ESL courses and academic major-related courses (Nishimura, 2009). Nishimura (2009) stated that there are two types of activities that international students need to be aware of. First, the important activities have an outcome that leads to achieving the student's own goals and objectives. Second by contrast, urgent activities are often associated with the achievement of group members' goals and objectives. Japanese students need to develop action and priority plans, prioritize activities, and evaluate the importance and urgency of different activities (Nishimura, 2009).

The exchange students asserted that there were only a few opportunities to interact with American classmates when they participated in group work, because American classmates rarely showed much interest in communicating or socializing with them. American classmates avoided the Japanese students by acting in socially distant and impolite ways. According to Hyland (2005), there are two dimensions in group work. The term 'interactive dimension' refers to how all group members shape and constrain a text or content so that a presenter and listeners (group mates) develop knowledge, interests, and rhetorical expectations. This dimension focuses on "organizing discourse rather than experiences" (Hyland, 2005, p. 49) in order to respond to the needs of listeners. By contrast, the "interactional dimension" refers to how a speaker expressess his or her voice or message or new perspectives on a certain topic and how the listeners evaluate the speaker's presentation. In the present study, some Japanese students and group mates attempted to find and share mutual knowledge and interests (interactive dimension) during group work, but they were unable to construct meaningful and progressive interactions related to their own experiences (interactional dimension).

The Japanese students felt isolated or marginalized in the class environment. What's more, several professors urged them to withdraw from the courses in which they had enrolled. However, college students' sense of belonging and their academic motivation are tied to faculty attributes such as warmth, openness, and organization (Freeman, Anderman, \& Jensen, 2007). 
Students must be comfortable enough to participate actively in class (Alkandari, 2012). The Japanese students in this study were appreciative when their professors were concerned with respecting students' academic positions during classroom participation, lectures, and various activities - including exams and journal writing. However, their professors provided no extra support for these students' academic success. They understood that there was social distance that adversely affected international students' academic performances.

Interestingly, the students noted that the professors who encouraged international students to withdraw from the course tended to use a passive teaching style rather than active teaching styles. A passive teaching style emphasizes convenient and expeditious mode of imparting knowledge and introducing basic principles to students (Whetten \& Clark, 1996). By contrast, active teaching styles help students engage in activities and think about what they are doing in the classroom (Bonwell \& Eison, 1991). The professors of these Japanese exchange students did not have an active teaching style relevant to a culturally, socially, and academically inclusive classroom environment.

According to Weidman, Twale, and Stein (2001), faculty should serve responsible roles so as to represent three core elements (knowledge acquisition, investment, and involvement) in the academic socialization process of all students. Socialization and mentorship by professors are of critical importance for Japanese exchange students, who need to acquire the skills and abilities necessary to be academically and socially successful. In this study, the exchange students felt that the professors did not show any willingness to help them progress academically unless they asked for help and support. The students had hoped the professors would become persons they could talk to or consult with outside of class (Tam et al., 2009). Pratt, Kelly, and Wong (1999) observe that effective teachers in Asian countries (e.g., Japan, China) are described as having protective and caring relationships with students. Additionally, they sometimes fulfill the role of a parent, including guiding the intellectual, moral, and personal development of students (Tam et al., 2009).

The Japanese exchange students in this study sincerely appreciated how the Japanese student organization served in a counseling role to support their study abroad experience. Liao, Rounds, and Klein (2005) asserted that students in Asian cultures are quite hesitant to share intimate thoughts and feelings with a stranger such as a counselor, ESL course instructor, or staff in Office of International Students. Rather than seeking professional assistance, they often ask for help from their friends and family during difficult times (Yeh \& Wang, 2000). In this study, the Japanese student organization served an important role in resolving academic and social issues faced by the Japanese students.

\section{Delimitations and Limitations}

This study has delimitations and limitations. First, the participants were deliberately selected from just one public research university in the Midwest of the US. Statistically speaking, therefore, the findings are not generalizable. From a qualitative perspective, however, the reader may assume transferability to the contexts of colleges or universities elsewhere in those cases where there are contextual similarities with Japanese students (Leininger, 1994). Second, the study was delimited to the views of Japanese students only. This may be judged as a limitation as well. Although the voices of Japanese students studying abroad do not need to be legitimatized by the perspectives of others, future research might expand the discourse by adding the voices of professors and fellow students from the host country. A study limitation was also the small 
number of participants and yet they had rather diverse backgrounds, experiences, cultures, and dialects. Qualitative inquiries, including case studies, typically use small samples and in the logic of maximum variation sampling, the intent is to capture and describe the central themes that cut across a vast array of participant variation (Patton, 2002). Our intent in using this sampling approach was to uncover common themes reflecting the diversity of Japanese students.

\section{Recommendations}

In their academic and social sojourn at a university in the US, the Japanese students' cultural and linguistic differences, social pattern of collectivism, and negative experiences with professors and other students created and exacerbated their academic and social difficulties. They felt alienated and marginalized, alone and isolated. These findings are consistent with previous findings involving Asian international students at US colleges and universities (e.g., Sato \& Hodge, 2009). American colleges and universities still need to do more to promote cultural learning and positive relationship-building between international students and all other students.

Academic units should encourage and help Japanese students develop and maintain attitudes of multicultural openness through relationship-building initiatives and opportunities for networking with peers of the host country, which might lessen the dangers of experiencing isolation, cultural conflicts, and academic and/or social dilemmas (Yakuina, Weigold, Weigold, Harcegovac, \& Elsayed, 2013). They must be taught how to take initiative and how to reframe cross-cultural stressors as opportunities for personal and professional growth. Further research indicates that developing active coping strategies are valuable mechanisms for Japanese exchange students (Yakuina et al., 2013). Academic units can facilitate the process of exchange students finding and connecting with English conversation partners and host families, which would permit them to practice English learning with supportive others. Moreover, academic units should develop or identify existing multicultural retreat organizations that American and international students can join in; for example, to participate in workshops on cultural, social, and academic adjustment strategies that would help the exchange students overcome barriers to successful transition into American universities.

To reiterate, Japanese exchange students must develop openness to diverse cultural ways of life on the host college campus, which will enhance their understanding of America's cultural tilt toward individualism versus Japan's cultural tilt toward collectivism (Yakuina et al., 2013). Academic and social adjustment in terms of individualism and collectivism should be included as part of orientation programs for international students. Japanese exchange students may show curiosity, which will help them approach social practice of individualism. More contact with students from diverse cultural and social backgrounds promotes greater understanding among international and American students and creates a multicultural openness (Yakuina et al., 2013).

Japanese exchange students must increase their contact with American students on campus as they seek to adjust to the culture and educational environment of American universities. Mentoring by American students or Japanese students who have spent adequate time- perhaps even years at the respective universities- will help Japanese exchange students in their efforts to adjust to the university's culture as they establish intergroup relationships. University professors can promote social and academic interactions as well through directed group work (e.g., American and international students assigned to work together on various academic tasks). A word of caution, however, group work must be structured in ways that allow 
all students to contribute meaningfully to the group discussion or work (Leki, 2001; Sato et al., 2011).

Lastly, college and university faculty and administrators need to become more aware of the increasing enrollment of international students on US campuses and become more sensitive to the needs of these academic and social sojourners (Sato \& Hodge, 2009). In collaboration with offices of international affairs, academic units need to sponsor mandatory programs on cultural, social and academic adjustment and seminars to address issues concerning international students' academic and social experiences, discrimination and marginalization, diversity, and internationalism. It is also important to institutionalize a commitment to student diversity (including internationalism), and colleges and universities should include in the promotion and tenure process an evaluation of faculty activities associated with promoting such diversity. This type of accountability measure would encourage faculty to more regularly engage in activities supportive of diversity, which might lead to them acquiring a heightened awareness of the kinds of issues presented in this paper (Hodge \& Wiggins, 2010).

To better support Japanese students, we encourage academic departments, administrators, faculty, and all students to respect, value, and embrace origins, languages, and cultures of Japanese students. This will contribute to a greater appreciation for the richness of diversity and to meaningful academic and social experiences available at American universities for all students.

\section{REFERENCES}

AlKandari, N. (2012). Students' communication and positive outcomes in college classrooms. Education, 133(1), 19-30.

Banville, D., Desrosiers, P., \& Genet-Volet, Y. (2000). Translating questionnaires and inventories using a cross-cultural translation technique. Journal of Teaching in Physical Education, 19, 374-387.

Barratt, M. \& Huba, M. (1994). Factors related to international undergraduate student adjustment in an American community. College Student Journal, 28(4): 422-436.

Bevis, T. B. (2002). At a glance: International students in the United States. International Educator, 11(3), 12-17.

Bonwell, C., \& Eison, J. (1991). Active learning: Creating excitement in the classroom, ASHEERIC Higher Education Report No. 1. Washington, DC: The George Washington University, School of Education and Higher Education.

Bradly, D., \& Bradly, M. (1984). Problems of Asian students in Australia: Language, culture, and education. Canberra, ACT: Australian Government Publishing Service.

Brantlinger, E., Jimenez, R., Klingner, J., Pugach, M., \& Richardson, V. (2005). Qualitative studies in special education. Exceptional Children, 71, 195-207.

Bretag, T., Horrocks, S., \& Smith, J. (2002). Developing classroom practice to support NESB students in information systems courses: Some preliminary findings. International Education Journal, 3, 57-69.

Choi, T. (2006). Asian international students' academic adjustments in a U.S. graduate school and Stanton-Salazar's framework. Pacific Asian Education, 18(2), 51-68.

Chronicle of Higher Education. (2009). Number of foreign students in U.S. hit new high last year. Retrieved from http://chronicle.com/article/Number-of-Foreign-Students-in/49142/ 
Cross, S. E. (1995). Self-construrals, coping, and stress in cross - cultural adaptation. Journal of Cross-Cultural Psychology, 26(6), 673-697.

Gay, L. R. (1996). Educational research: Competencies for analysis and application (5th ed.). Upper Saddle River, NJ: Prentice-Hall.

Gravetter, F. J., \& Wallnau, L. B. (1996). Statistics for the behavioral sciences $\left(4^{\text {th }}\right.$ ed.). St. Paul, MN: West Publishing.

Gudykunst, W. B., \& Hammer, M. R. (1988). Strangers and hosts: an uncertainty reduction based theory of intercultural adaptation. In Kim, Y. Y., \& Gudykunst, W. B. (Eds.). Cross-cultural adaptation: current approaches. (pp. 106-139). Newbury Park, CA: Sage.

Freeman, T. M., Anderman, L. H., \& Jensen, J. M. (2007). Sense of belonging in college freshmen at the classroom and campus levels. The Journal of Experimental Education, 75(3), 203-220.

Harrison, P. (2002). Educational exchange for international understanding. International Educator, 11(4), 2-4.

Hellsten, M., \& Prescott, A. (2004). Learning at university: The international students experience. International Education Journal, 5, 344-351.

Hodge, S. R., Lieberman, L. J., \& Murata, N. (2012). Essentials of teaching physical education: Culture, diversity, and inclusion. Scottsdale, AZ: Holcomb Hathaway.

Hodge, S. R., \& Wiggins, D. K. (2010). The African American experience in physical education and kinesiology: Plight, pitfalls, and possibilities. Quest, 62, 35-60.

Hyland, K. (2005). Metadiscourse: Exploring Interaction in Writing. London: Continuum. Institute for International Education. (2007). Open-doors 2007 online: Report on international educational exchange. New York: Retrieved from http://www.opendoors.iienetwork.org/

Institute for International Education Network. (2014). Open-doors 2014 online: Report on international educational exchange. New York: Author. Retrieved from http://www.iie.org

Jones, E. A., \& Ratcliff, G. (1993). Critical thinking skills for college students. Unpublished (Eric Document Reproduction Services No. ED 358 772). National Center on Postsecondary Teaching, Learning, and Assessment, University Park.

Kaczmarek, P. G., Matlock, G., Merta, R., Ames, M. H., \& Ross, M. (1994). An assessment of international college student adjustment. International Journal for the Advancement of Counseling, 17, 241-247.

Kobayashi, E., Kerbo, H., \& Sharp, S. (2010). Differences in individualistic and collectivistic tendencies among college students in Japan and the United States. International Journal of Comparative Sociology, 51(1-2), 59-84.

Leininger, M. (1994). Evaluation criteria and critique of qualitative research studies. In J. M. Morse (Eds.). Critical issues in qualitative research methods (pp. 95-115). Thousand Oaks, CA: Sage.

Leki, I. (2001). "A narrow thinking system": Nonnative-English-speaking students in group projects across the curriculum. TESOL Quarterly, 35(1), 39-67.

Liao, H., Rounds, J., \& Klein, A. G. (2005). A test of Cramer's (1999) help seeking model and acculturation effects with Asian and Asian American college students. Journal of Counseling Psychology, 52(3), 400-411. 
Lincoln, Y. S., \& Guba, E. G. (1986). But is it rigorous? Trustworthiness and authenticity in naturalistic evaluation. In D. D. Williams (Ed.), Naturalistic evaluation: New directions for evaluation (pp. 15-25). San Francisco: Jossey-Bass.

Merriam, S. B. (1998). Qualitative research and case study applications in education. San Francisco, CA: Jossey-Bass.

Nilsson, J. E., Butler, J. Shouse, S., \& Joshi, C. (2008). The relationship among perfectionism, acculturation, and stress in Asian international students. Journal of College Counseling, $11,147-158$.

Nishimura, S. (2009). Process of "aseri" as experienced in the daily life of young adults. Japanese Journal of Psychology, 80(5), 381-388.

Okonogi, K. (1992). Amae as seen in diverse interpersonal interactions. Infant Mental Health Journal, 13, 18-25.

Open Doors 2014 Report. (2014). International students in the United States and Study Abroad by Anmerican students are at all-time high. New York: Author. Retrieved from http://www.iie.org/Who-We-Are/News-and-Events/Press-Center/Press-

Releases/2014/2014-11-17-Open-Doors-Data

Patton, M. Q. (2002). Qualitative research and evaluation methods (3 ${ }^{\text {rd }}$ ed.). Thousand Oaks, CA: Sage.

Pratt, D. D., Kelly, M., \& Wong, W. S. S. (1999). Chinese conceptions of "effective teaching" in Hog Kong: Towards culturally sensitive evaluation of teaching. International Journal of Lifelong Education, 18, 241-258.

Robie, C. \& Ryan, A. M. (1996). Structural equivalence of a measure of cross-cultural adjustment. Educational and Psychological Measurement, 56, 514-521.

Samuel, E. (2004). Racism in peer-group interactions: South Asian students' experiences in Canadian academe. Journal of College Student Development, 45(4), 407-424.

Sato, T., \& Hodge, S. R. (2009). Asian international doctoral students' experiences at two American universities: Assimilation, accommodation, and resistance. Journal of Diversity in Higher Education, 2(3), 136-148.

Sato, T., Hodge, S. R., \& Burge-Hall, V. (2011). International student - athletes' academic, athletic, and social experiences at a historically black university in America. Journal for the Study of Sports and Athletes in Education, 5(1), 45-72.

Schwartz, S. H. (1990). Individualism - collectivism: Critique and proposed refinements. Journal of Cross-Cultural Psychology, 21, 139-157.

Seidman, I. (1998). Interviewing as qualitative research: a guide for researchers in education and the social sciences ( $2^{\text {nd }}$ ed). New York: Teacher College Press.

Spurling, N. (2006). Exploring adjustment: The social situation of Chinese students in UK higher education. Learning and Teaching in the Social Science, 3(2), 95-117.

Tam, K. Y., Heng, M. A. and Jiang, G. H. (2009). What undergraduate students in China say about their professors' teaching. Teaching in Higher Education, 14(2), 147-159.

Vallerand, R. J. (1989). Vers une méthodologie de validation trans-culturelle de questionnaires psychologiques: Implications pour la recherche en langue française. Psychologie Canadienne, 30, 662-680.

Weidman, J. C., Twale, D. J., \& Stein, E. L. (2001). Socialization of graduate and professional students in higher education: A perilous passage? San Francisco, CA: Jossey-Bass.

Whetten, D. A., \& Clark, S. C. (1996). An integrated model for teaching management skills. Journal of Management Education, 20, 152-181. 
Wilton, L., \& Constantine, M. G. (2003). Length of residence, cultural adjustment difficulties, and psychological distress symptoms in Asian and Latin American international college students. Journal of College Counseling, 6, 177-186.

Woodrow, L. (2006). Anxiety and speaking English as a second language. Regional Language Center Journal, 37(3), 308-32.

Yakunina, E. S., Weigold, I. K., Weigold, A., Harcegovac, S., \& Elsayed, N. (2013). International students' personal and multicultural strengths: Reducing acculturative stress and promoting adjustment. Journal of Counseling \& Development, 91, 216-223.

Yeh, C. J. \& Wang, Y-W. (2000). Asian American coping attitudes, sources, and practices: Implications for indigenous counseling strategies. Journal of College Student Development, 41(1), 94-103.

Zhang, Y., \& Mi, Y. (2010). Another look at the language difficulties of international students. Journal of Studies in International Education, 14(4), 371-388.

\begin{abstract}
About the Author
TAKAHIRO SATO, Ph.D., is an Assistant Professor in School of Teaching, Learning, \& Curriculum Studies at Kent State University, Kent, OH. His scholarship and research focuses on multicultural physical education, inclusion in sport, and diversity in higher education.
\end{abstract}

SAMUEL R. HODGE, Ph.D., is a Professor in Department of Human Sciences at The Ohio State University, Columbus, $\mathrm{OH}$. His scholarship and research focuses on social justice pedagogies, diversity, disability in physical education, and diversity in higher education. 